\title{
The additional iron cable fixation between proximal patella and tibial tuberosity to treat AO/OTA 34C3 patellar fracture
}

\section{Dongzheng Zhang}

Hebei Medical University Third Affiliated Hospital https://orcid.org/0000-0001-6581-971X

Yong Shen ( $\sim$ shenyong2017@sina.com )

Hebei Medical University Third Affiliated Hospital

\section{Technical note}

Keywords: patellar fracture, cable fixation

Posted Date: November 17th, 2020

DOI: https://doi.org/10.21203/rs.3.rs-25683/v2

License: (c) (i) This work is licensed under a Creative Commons Attribution 4.0 International License.

Read Full License 


\section{Abstract}

\section{Background:}

It is very difficult to deal with AO/OTA 34C3 patellar fracture. Although the modified Kirschner wire tension band, the cerclage and plate has been proposed to treat it, the result is not very good. We found that if the fixation was not firm enough after the modified Kirschner wire tension band with or without the cerclage had been carried out, the additional iron cable fixation between proximal patella and tibial tuberosity could resolve it effectively.

\section{Methods:}

Retrospective analysis was completed. 21 patients with AO/OTA 34C3 patellar fracture were treated in our department from January 2014 to January 2018. They were divided into 2 groups according to the operation plan. Group 1 (normal group), with 12 patients, was treated with modified Kirschner wire tension band with or without cerclage cable. Group 2 (cable group), with 9 patients, was treated with the additional iron cable fixation between proximal patella and tibial tuberosity when the fixation was not firm enough after the modified Kirschner wire tension band with or without the cerclage had been completed.

\section{Results:}

The two groups of the age, sex ratio, trauma mechanism, operation time, free articular fragment, comorbidity and follow-up time had no significant statistical difference $(P>0.05)$. There was no significant statistical difference between the two groups of the clinical results. (such as Bostman total score and its specific individual score, the excellent and good ratio, the complications, and the bone union time, etc.) $(P>0.05)$.

\section{Conclusions:}

To deal with AO/OTA 34C3 patellar fracture, when the fixation of modified Kirschner wire tension band with or without the cerclage cable is not firm enough, the additional iron cable fixation between proximal patella and tibial tuberosity can resolve it effectively.

\section{Background}

With the popularity of motor vehicles, the traffic accidents have become higher than ever in China. The patella can be hit directly by the dashboard ${ }^{[1.2]}$, which leads to multi-fragmentary fractures. The quality of the patellar bone usually is good.

At the same time, Chinese elderly society is coming. The aged people are easy to stumble to kneel on the ground ${ }^{[1.2 .3 .4]}$, which leads to transverse patellar fracture. The proximal fragment is mostly pulled away 
by quadriceps, while the distal fragment is pincered by the distal femur and the ground. On the basis of osteoporosis, the distal patella becomes multi-fragmentary fractures.

As a result, both Mechanisms of injury will form AO/OTA ${ }^{[5]} 34 \mathrm{C} 3$ patellar fracture that is extremely difficult to cure.

In the past, we would do our best to fix the patella. If the fixation was not firm, we could only add external fixation. But the complications of external fixation such as joint stiffness and adhesion, muscle atrophy, and deep venous thrombosis maybe occur. And the patients could not live by themselves in the early time after operation. If the internal fixation failed, the disputes would be inevitable. Not only did the patients doubt the quality of the operation, but also the operators were no longer confident to deal with the fracture.

Since January 2014, when the internal fixation was found to be loose or the knee joint was unable to resist the traction of joint autonomous movement. The additional figure-8 iron cable fixation between proximal patella and tibial tuberosity would be performed, which had achieved perfect results. Both doctors and patients were satisfied.

\section{Methods}

Retrospective analysis was completed. Although there were many people who got patellar fracture, the people who got AO/OTA ${ }^{[5]} 34 \mathrm{C} 3$ patellar fracture were rare. Therefore, the sample size of this study was small. Only 21 patients with AO/OTA ${ }^{[5]} 34 \mathrm{C} 3$ patellar fracture were treated in our department from January 2014 to January 2018. 12 patients were treated with modified Kirschner wire tension band with or without cerclage cable and were classified into group 1 (common group). On the basis of group 1 fixation, 9 patients who underwent additional figure-8 iron cable fixation between proximal patella and tibial tuberosity consisted of group 2(cable group) when the simple internal fixation of group 1 was found to be loose or the knee joint was unable to resist the traction of joint autonomous movement. So this study is not a randomized controlled study.

\section{Surgery techniques}

After successful lumbar anesthesia, the patient was put on the operating table in supine. After conventional preparation, the anterior mid-line incision of patella was adopted to expose the fracture area.

The patellar fracture was fixed by modified Kirschner wire tension band ${ }^{[6,7]}$ with or without the cerclage cable $^{[8]}$. (For large free articular fragment, we reduced it with proximal patella and fixed it with Kirschner wire at direct vision.) If the patella fixation was not loose after more than 30 times of repeated full-range passive knee joint movement, then the incision could be closed to finish the operation. 
If the patella fixation was loose before 30 times of knee joint movement, the modified Kirschner wire tension band could not performed perfectly, the patella and patellar tendon was not connected firmly, or the operator considered the fixation could not resist the traction of lower limb autonomous movement, then the additional figure-8 iron cable fixation between proximal patella and tibial tuberosity should be carried out.

\section{Establishment and fixation of proximal patella.}

A relatively complete proximal patella could be established when Kirschner wire or screw penetrated the proximal fragments under direct vision. If size and bone quality of the proximal patella was good enough, then transverse drilling through proximal patella (the diameter of drill bit was $1.2 \mathrm{~mm}$, and the diameter of iron cable was $1 \mathrm{~mm}$.) could be adopted, and the cable was inserted to finish the fixation. Otherwise, the iron cable should fix the proximal patella like the cerclage.

2. Fixation of tibial tuberosity.

Percutaneously, $1.2 \mathrm{~mm}$ diameter drill bit transversely drilled the corresponding area of the tibial tuberosity ( $1 \mathrm{~cm}$ behind the cortex of the tibial tuberosity and $2 \mathrm{~cm}$ away from the tibial plateau), the iron cable was guided subcutaneously to pass through the bone hole to make figure-8 fixation.

\section{Adjustment of cable tightness.}

When the knee joint was flexed completely and the patellar tendon should be slightly loose, the cable button was tightened to complete the final fixation. (Typical cases Figures 1 and 2.)

A,B pre-operation. A 31-year-old male was hit by car. Multi-fragmentary fractures with one free articular fragment were checked out in left knee. The longitudinal length of the proximal patella fragment was less than $1 / 3$ of the longitudinal length of the patella. C,D. post-operation. The free articular fragment was fixed on the proximal patella by Kirschner wire under direct vision. The other fragments were properly restored and fixed through cerclage cable. After trying, the tension band could not be implemented at all. Because the longitudinal length of the proximal patellar fragment was short, the cable fixed the proximal patella like the cerclage. Finally, the figure-8 cable fixation between the proximal patella and the tibial tuberosity was completed. The passive knee joint activity test was carried out. The internal fixation of the patella was firm enough. The patient recovered well after the operation.

E,F pre-operation. A 62-year-old male stumbled carelessly and knelt on his left knee. The distal patella was crushed to loosening and became multi-fragmentary fractures with one free articular fragment. The patella was osteoporotic, the distal patella was like sand. G,H post-operation. A fine Kirschner wire was used to fix the reduced free articular fragment under direct vision. Modified Kirschner wire tension band was tried to fix other fragments. However, the distal patella was too loose and it could be passed by with free hand. And the connection between the distal patella and patellar tendon was loose. Therefore, the patella shape was maintained by cerclage cable. Because the passive knee joint movement test couldn't be carried out. Thereby, the figure-8 cable fixation between the proximal patella and the tibial tuberosity 
was implemented. (The proximal patella was fixed with cable encircling because of osteoporosis.) The knee joint activity test was performed to certify the firmness of the fixation. The patient recovered well after the operation.

\section{postoperative management}

The postoperative treatment was the same in the two groups. The next day after the operation, after the anesthesia was fully recovered, the patient was encouraged to act knee joint autonomously. Within 4 weeks after the operation, the patient could walk with crutches and the wounded lower limb should avoid weight bearing. 4-8 weeks after operation, the affected limb could bear less than $20 \mathrm{~kg}$. 8-12 weeks after operation, the patient could walk with a single crutch in the un-injury side. 12 weeks after operation, the patient could walk freely. The patients were reexamined 1, 2 and 3 months after the operation and every 3 months thereafter. Internal fixation was removed 15-18 months after operation. After that, the examination should be performed once or twice.

\section{Statistical methods}

SPSS 20.0 (IBM Corp.) was used to conduct the statistical analysis of all data. For comparison of the normally distributed variables, a two-tailed Student's t-test was used; for non-normal distributions, the Mann-Whitney $U$ test was used. Differences in proportions for categorical variables were assessed with the use of Fisher exact test. The $P$ value was set at a significance level of 0.05 .

\section{Results}


Table 1. Clinical demographic data between the 2 groups.

\begin{tabular}{|c|c|c|c|}
\hline Variables & Common group (group 1) & Cable group (group 2) & $P$ \\
\hline Patients, cases & 12 & 9 & \\
\hline \multicolumn{4}{|l|}{ A0 classification, cases } \\
\hline C3 & 12 & 9 & \\
\hline Age, years & $53.5 \pm 19.3$ & $39.0 \pm 16.7$ & 0.087 \\
\hline \multicolumn{4}{|l|}{ Gender, cases } \\
\hline Male & 9 & 8 & 0.603 \\
\hline Female & 3 & 1 & \\
\hline \multicolumn{4}{|l|}{ Injury reason, cases } \\
\hline Car accident & 9 & 7 & 1.000 \\
\hline Tumbling & 3 & 2 & \\
\hline \multicolumn{4}{|c|}{ Big free articular fragment, cases } \\
\hline Yes & 5 & 3 & 1.000 \\
\hline No & 7 & 6 & \\
\hline \multicolumn{4}{|l|}{ Comorbidity, cases } \\
\hline Yes & 4 & 3 & 1.000 \\
\hline No & 8 & 6 & \\
\hline Operation time, minutes & $61.25 \pm 4.54$ & $62.51 \pm 4.10$ & 0.505 \\
\hline Follow-up, months & $20.75 \pm 2.70$ & $21.00 \pm 2.60$ & 0.821 \\
\hline
\end{tabular}

Data are number of patients and mean \pm standard deviation.

There were 12 patients in the common group and 9 patients in the cable group. Both groups of patients were A034C3 patellar fracture. The age, sex ratio, trauma mechanism, operation time, free articular fragment, comorbidity and follow-up time of the two groups had no significant statistical difference $(P>0.05)$. table 1区

1. The mean age of the common group was $53.5 \pm 19.3$ years (range $20-83$ years), while the mean age of the cable group was $39.0 \pm 16.7$ years (range $20-64$ years).

2. There were 9 males and 3 females in the common group and 8 males and 1 female in the cable group.

3. 9 patients in the common group were injured due to traffic accidents, 3 were injured due to tumbling and kneeling, 7 patients in the cable group were injured due to traffic accidents, and 2 were injured due to tumbling and kneeling.

4. In the common group, 5 patients had free articular fragment, while in the cable group, 3 patients had free articular fragment.

5. In the common group, 4 patients had combined injuries in other parts, 1 case had rib fracture, 2 cases had unilateral radial fracture, and 1 case had bilateral radial fracture and brain injury. In the cable group, 3 patients had combined injuries in other parts, 2 cases had brain trauma and 1 case had ipsilateral femoral shaft fracture.

6. The mean operation time was $61.25 \pm 4.54$ minutes (range $55-70$ minutes) in the common group and $62.51 \pm 4.10$ minutes (range $55-68$ minutes) in the cable group. 
7. The mean follow-up time of the common group was $20.75 \pm 2.70$ months ( range $18-24$ months). The mean follow-up time of the cable group was $21.00 \pm 2.60$ months (range 18-24 months).

Table 2. Clinical results of the 2 groups.

\begin{tabular}{llll}
\hline Outcome variables & Common group (group 1) & Cable group (group 2) & P \\
\hline Bostman grading scale & & & \\
Range of movement. & $6.00 \pm 0.00$ & $6.00 \pm 0.00$ & 1.000 \\
Pain & $5.00 \pm 1.48$ & $5.00 \pm 1.50$ & 1.000 \\
Work & $4.00 \pm 0.00$ & $4.00 \pm 0.00$ & 1.000 \\
Atrophy of quadriceps femoris & $4.00 \pm 0.00$ & $4.00 \pm 0.00$ & 1.000 \\
Assistance in walking & $4.00 \pm 0.00$ & $4.00 \pm 0.00$ & 1.000 \\
Effusion & $1.75 \pm 0.45$ & $1.78 \pm 0.44$ & 0.885 \\
Giving way & $2.00 \pm 0.00$ & $2.00 \pm 0.00$ & 1.000 \\
Stair-climbing & $1.75 \pm 0.45$ & $1.78 \pm 0.44$ & 0.885 \\
Total score & $28.50 \pm 2.28$ & $28.56 \pm 2.24$ & 0.966 \\
Excellent (28-30) & 8 & 6 & 1.000 \\
Good (20-27) & 4 & 3 & \\
Complications, cases & & & \\
Yes & 4 & 4 & 0.673 \\
No & 8 & 5 & \\
Clinical bone union, months & $2.50 \pm 0.52$ & $2.44 \pm 0.53$ & 0.806 \\
\hline
\end{tabular}

Data are number of patients and mean \pm standard deviation.

The clinical results of the two groups, (such as Bostman ${ }^{[9]}$ total score and its specific individual score, the excellent and good ratio, the complications, and the bone union time, etc.) had no significant statistical

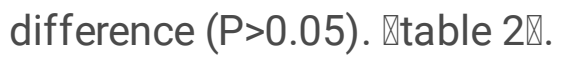

1. Both groups of patients had no obvious limitation in the range of knee joint movement,.

2. In terms of knee joint pain, 4 patients in the common group had slight pain after overwork. 3 patients in the cable group had slight pain.

3. Both groups of patients could return to their original work.

4. There was no obvious quadriceps femoris atrophy in both groups.

5. Both groups of patients didn't need auxiliary tools to walk.

6. 3 patients of the common group and 2 patients of the cable group had joint effusion occasionally, because the joint surface was not smooth enough.

7. Both groups of patients did not have giving way.

8. Because of the uneven articular surface, 3 patients in the common group and 2 patients in the cable group had slight discomfort when they climbed the stairs.

9. The mean Bostman score in the common group was $28.50 \pm 2.28$ points (range $25-30$ points). The mean Bostman score in the cable group was $28.56 \pm 2.24$ points (range $25-30$ points). 
10. 8 patients got excellent results and 4 got good results in the common group. The cable group had 6 excellent outcomes and 3 good outcomes.

11. As for complications, the implant loosening and displacement was discovered in 1 patient, the uneven patellar articular surface were found in 3 patients in 12 months after in the common group. In the cable group, 2 patients had implant loosening 3 months after operation. The uneven patellar articular surface of 2 patients were found 12 months after operation. However, there was no cable broken, or the cable cut out of the bone.

12. According to clinical and radiographic results, all patients achieved bony union by $2.44 \pm 0.53$ months (range 2-3 months) in the common group and 2.50 \pm 0.52 months (range 2-3 months) in the cable group.

It can be seen that there is no significant statistical difference between the two groups, no matter the demographic data before operation or the results after operation. However, the implementation of the additional cable fixation avoids the adverse consequences caused by external fixation when internal fixation of patellar fracture is insufficient.

\section{Discussion}

To deal with AO/OTA 34C3 patellar fracture, German ${ }^{[1]} \square$ American ${ }^{[10]}$ and Switzerland ${ }^{[2]}$ experts proposed special plate. However, the plate is not easy to popularize because the fragment is small and loose. (For eastern people, the body is short, the fragment is more small and loose. ) There is no space for fixing screws.

Although patellar multi-fragmentary fractures are difficult to treat, they are treated according to two rules. The first is to restore the congruous articular surface and the second is to recover the patellar tensile strength $^{[11]}$.

To restore articular surface, it is important to fix the free articular fragment. Of the 21 patients with $\mathrm{AO} / \mathrm{OTA}^{[5]} 34 \mathrm{C} 3$ patellar fracture that we implemented, there were 8 patients with free articular fragment. The South Korean author ${ }^{[3]}$ suggested to fix the Loose articular fragment with headless compression screw, but we found that the articular fragments usually were thin, we fixed them with Kirschner wire under direct vision. In the follow-up, although no fragments were found to fall off, 2 of the 8 patients still suffered from unevenness of articular surface. In the 12-month follow-up after operation, 5 of the 21 $\mathrm{AO} / \mathrm{OTA}^{[5]} 34 \mathrm{C} 3$ patients showed unevenness of the articular surface. Therefore, it is still a long way to restore the articular surface of AO/OTA ${ }^{[5]} 34 \mathrm{C} 3$ patellar fracture.

To restore the tensile strength of patella, we should not only focus on the treatment of patella, but also focus on the restoration of the extensor mechanism ${ }^{[11]}$. The fact is that the additional cable fixation between proximal patella and tibial tuberosity can replace knee extension device. 
The additional cable fixation requires relatively intact proximal patella. Although patellar fracture is type $\mathrm{AO} / \mathrm{OTA}^{[5]} 34 \mathrm{C} 3$, we find that the comminuted area of patellar fracture is often located in the middle or distal part of patella. Actually, from January 2014 to January 2018 in our department, of the 48 patellar fracture, only one was proximal patellar multi-fragmentary fractures, and the rest were middle and distal patellar multi-fragmentary fractures. We think that this is definitely related to the shape and position of the patella and the pulling to the patella. The upper of the patella is large while the lower of the patella is small. The proximal end of the patella is pulled by the quadriceps femoris muscle which is the most powerful in the body. As elaborated by Afsar $\mathrm{E}^{[12]}$ who did finite element analysis, the force on the proximal patella is the greatest. The unfractured patella is just in front of the broad distal femur. Once the patella is fractured, because of the pulling of the quadriceps femoris, the proximal patella is pulled away from the broad distal femur, escaping the crushing of the distal femur. The distal patella can't escape the crushing of the distal femur, so severe comminuted patellar fracture is always located in the middle or distal part of patella. Therefore, the proximal end of the proximal patella is intact usually or simple fracture. So the relative integrity of the proximal patella ean be achieved easily by simple transverse fixation. Thereby the foundation of the proximal patella can be prepared easily.

If the patient is young, the proximal patellar fragment is big, and the quality of the bone is good, we usually fix the proximal patella by inserting cable through the bone. When the patient is old with osteoporosis, (Because the osteoporosis is easy to occur in cancellous area ${ }^{[13,14]}$, the patella of the elderly becomes like an egg with soft core and hard shell.) or the patellar fragment is short, we will fix the proximal patella with cable similar to the cerclage method. So as to increase the resistance of the patella to cable cutting.

According to Lazaro's article ${ }^{[15]}$, who examined the patellar fracture with $\mathrm{CT}, 88 \%$ of patients had distal patellar pole fracture which sometimes made it difficult to fix the fracture area whether using Kirschner wire tension band or cerclage. Some people have proposed the partial patellectomy ${ }^{[2]} \rrbracket$ while others incline to suture patellar tendon on patella ${ }^{[15]}$. American ${ }^{[10]}$ and German ${ }^{[1]}$ experts suggested to suture and fix patellar tendon to the plate. But the repairment cannot be checked objectively in the above methods. The cast or brace external fixation sometimes has to be applied to protect the repairment. While the additional iron cable fixation between patella and tibial tuberosity can resolve the problem effectively. As the iron cable can be observed in X-ray. Through spanning the injury area, the additional cable fixation also can avoid the load bearing of the repairing area, which is beneficial to heal.

The minimally invasive technology of percutaneous drilling and subcutaneous inserting of cable in tibial tuberosity region greatly reduces the damage to local soft tissues.

Compared with iron wire ${ }^{[16]}$ fixation between patella and tibial tuberosity, the iron cable with the same diameter of the iron wire has obvious flexibility ${ }^{[17]}$, which will reduce the probability of cable fracture and the irritation to surrounding tissues. Otherwise, the diameter of the iron cable is big which will delay the bone cutting. With the healing of ligaments, even if the cable partially cut the bone area, it is difficult for the cable to continue cutting the bone because the ligament has played a role. 
Although, there were 21 patients with AO/OTA ${ }^{[5]} 34 \mathrm{C} 3$ patella fracture in our hospital, 9 patients $(43 \%)$ needed to be fixed by additional figure- 8 iron cable fixation, which indicated that modified Kirschner wire tension band with or without cerclage cable was not enough for complicated AO/OTA ${ }^{[5]} 34 \mathrm{C} 3$ patella fracture. Therefore, the AO/OTA ${ }^{[5]} 34 \mathrm{C} 3$ patella fracture should be got attention.

Because sufficient stress experiment was carried out during the operation, there was no worry about loosening of internal fixation after the operation, the postoperative rehabilitation of the two groups was the same. Both of two teams were allowed to take active postoperative exercise. The results also proved that all patients achieved excellent postoperative efficacy. Moreover, due to active exercise after operation, it was beneficial to reduce the occurrence of postoperative complications.

Therefore, The additional iron cable fixation between proximal patella and tibial tuberosity is a simple and effective method to treat AO/OTA ${ }^{[5]} 34 \mathrm{C} 3$ patellar fracture on the basis of modified Kirschner wire tension band fixation with or without the cerclage cable. In the end, the additional iron cable becomes the operator's safety belt and life line.

\section{Disadvantage}

Because Patellar fractures account for approximately $1 \%$ of all fractures ${ }^{[6]}$, the AO/OTA ${ }^{[5]} 34 \mathrm{C} 3$ patellar fractures are fewer. We only collected 21 cases through 4 years. So the sample size was relatively small.

\section{Conclusions}

To deal with AO/OTA ${ }^{[5]} 34 \mathrm{C} 3$ patellar fracture, when the fixation of modified Kirschner wire tension band with or without the cerclage cable is not firm enough, the additional iron cable fixation between proximal patella and tibial tuberosity can resolve it effectively.

\section{Declarations}

- Ethics approval and consent to participate

This study was approved by the Institutional Ethics Board of the Hebei Medical University Third Affiliated Hospital, and informed consent was obtained from all individual participants that were included in this study.

- Consent for publication

Not applicable.

- Availability of data and materials

Data requests are available from the corresponding author. 
- Competing interests

The authors declare that they have no competing interests.

- Funding

There was no direct funding source aligned to this study.

- Authors' contributions

Dongzheng Zhang is the main operator of the study.

- Acknowledgements

Not applicable.

- Authors' information (optional)

Not applicable.

\section{References}

1. Neumann MV, Niemeyer $P$, Sudkamp NP, et al. Patellar fractures--a review of classification, genesis and evaluation of treatment. Acta Chir Orthop Traumatol Cech. 2014;81(5):303-312.

2. Steinmetz S, Brügger A, Chauveau J, et al. Practical guidelines for the treatment of patellar fractures in adults. Swiss Med Wkly.2020 Jan 15;150:w20165

3. Suh KT, Suh JD. Open reduction and internal fixation of comminuted patellar fractures with headless compression screws and wiring technique. J Orthop Sci. 2018;23:97-104.

4. Qing-xian Tian, Yong Hai, Xin-ru Du, et al. Comparison of Tension-Band Wiring With the Cable Pin System in Patella Fractures: A Randomized Prospective Study. J Orthop Trauma 2015;29:e459-e463

5. Meinberg EG, Agel J, Roberts CS, et al. Fracture and dislocation classification compendium-2018. J Orthop Trauma. 2018. January;32(Suppl 1):S1-170.

6. Mehling I, Mehling A, Rommens PM. Comminuted patellar fractures. Curr Orthop. 2006;20(6):397404

7. Galla M, Lobenhoffer P. Patella fractures. Chirurg. 2005;76(10):987-99

8. Huang SL, Xue JL, Gao ZQ. Management of patellar fracture with titanium cable cerclage. Medicine (Baltimore) 2017;96:e8525.

9. Bostman O, Kiviluoto O, Nirhamo J. Comminuted displaced fractures of the patella. Injury 1981 Nov;13(3):196e202.

10. Lorich DG, Warner SJ, Schottel PC, et al. Multiplanar fixation for patella fractures using a low-profile mesh plate. J Orthop Trauma. 2015;29(12):504-510. 
11. Kakazu R, Archdeacon MT. Surgical management of patellar fractures. Orthop Clin North Am, 2016, 47: 77-83.

12. Afsar E, Taspinar F, Calik BB, et al. Use of the finite element analysis to determine stresses in the knee joints of osteoarthritis patients with different Q angles. Journal of the Brazilian Society of Mechanical Sciences and Engineering: (2017) 39:1061-1067

13. Dalstra M, Huiskes R. Load transfer across the pelvic bone. J Biomech 1995;28:715-24.

14. Burge R, Dawson-Hughes $B$, Solomon $\mathrm{DH}$, et al. Incidence and economic burden of osteoporosis related fractures in the United States, 2005-2025. J Bone Miner Res 2007;22:465-75.

15. Lazaro LE, Wellman DS, Pardee NC, et al. Effect of Computerized Tomography on Classification and Treatment Plan for Patellar Fractures. J Orthop Trauma.2013 Jun;27(6):336-44.

16. AHRBERG, A., JOSTEN, C.: Augmentation von Patellafrakturen und Patellarsehnenrupturen mittels McLaughlin Cerclage. Unfallchirurg, 110: 685-690, 2007.

17. Dickman CA, Papadopoulos SM, Crawford NR, et al. Comparative mechanical properties of spinal cable and wire fixation systems. Spine (Phila Pa 1976). 1997;22:596-604.

\section{Figures}

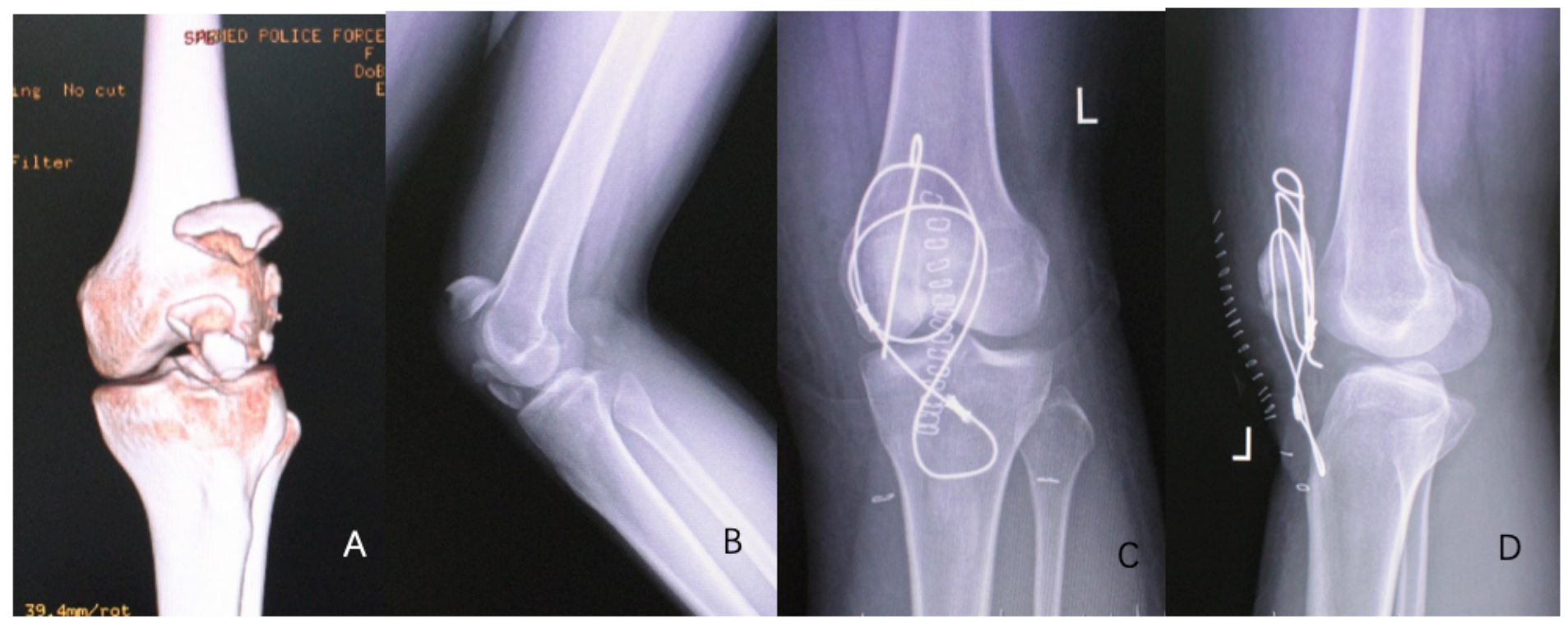

\section{Figure 1}

Typical case 1 A囚B. pre-operation. C,D. post-operation 


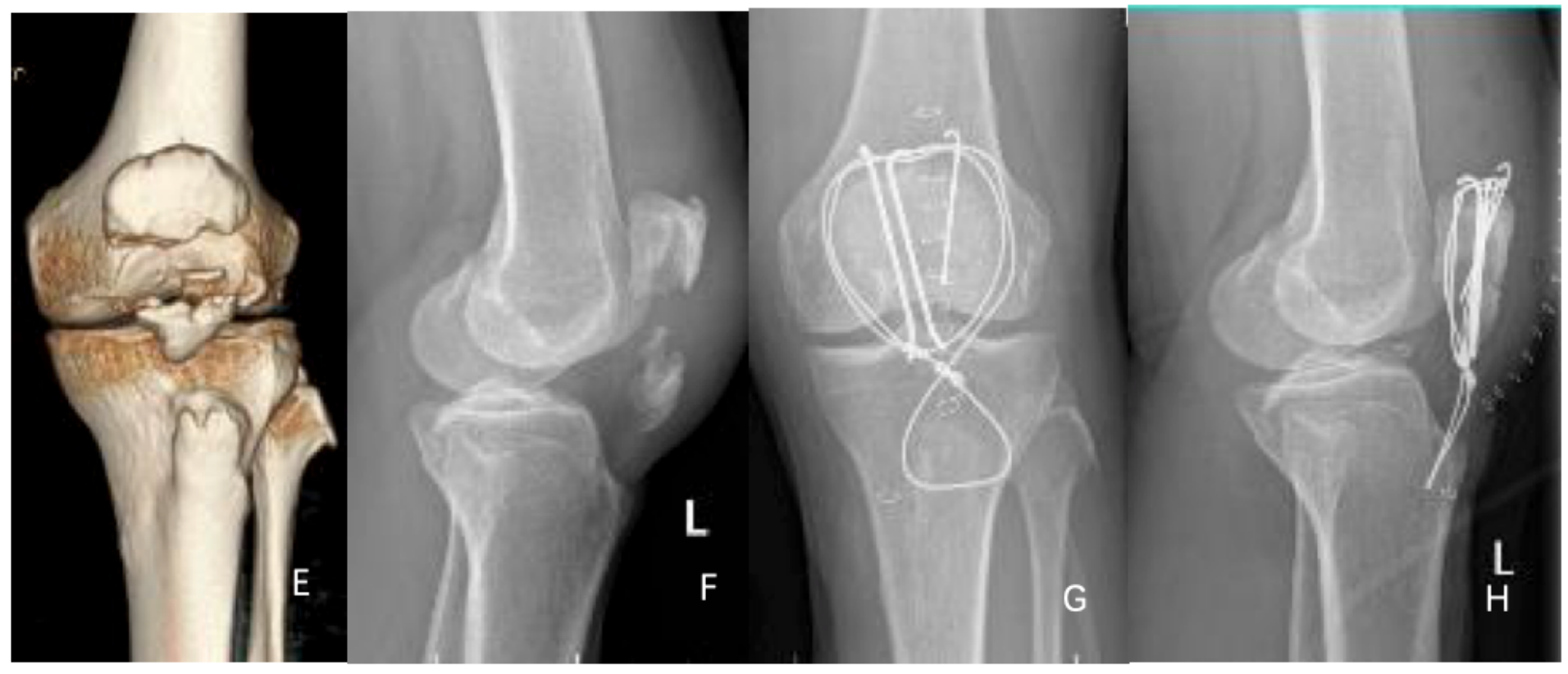

Figure 2

Typical case 2. E,F. pre-operation. G,H. post-operation 